\title{
Response time variability and response inhibition predict affective problems in adolescent girls, not in boys: the TRAILS study
}

\author{
Patricia A. M. van Deurzen - Jan K. Buitelaar · J. Agnes Brunnekreef • \\ Johan Ormel · Ruud B. Minderaa - Catharina A. Hartman • Anja C. Huizink • \\ Anne E. M. Speckens · A. J. Oldehinkel · Dorine I. E. Slaats-Willemse
}

Received: 9 October 2011/ Accepted: 8 February 2012/Published online: 22 February 2012

(C) The Author(s) 2012. This article is published with open access at Springerlink.com

\begin{abstract}
The present study examines the relationship between neurocognitive functioning and affective problems through adolescence, in a cross-sectional and longitudinal perspective. Baseline response speed, response speed variability, response inhibition, attentional flexibility and working memory were assessed in a cohort of 2,179 adolescents (age
\end{abstract}

P. A. M. van Deurzen $(\bowtie) \cdot$ J. K. Buitelaar .

A. E. M. Speckens · D. I. E. Slaats-Willemse

Department of Psychiatry, Donders Institute for Brain, Cognition and Behavior, Radboud University Nijmegen Medical Centre, 966, P.O. Box 9101, 6500 HB Nijmegen, The Netherlands

e-mail: P.vanDeurzen@psy.umcn.nl

P. A. M. van Deurzen · J. K. Buitelaar · D. I. E. Slaats-Willemse Karakter Child and Adolescent Psychiatry,

University Centre, Nijmegen, The Netherlands

\section{J. K. Buitelaar}

Department of Cognitive Neuroscience, Donders Institute for Brain, Cognition and Behavior, Radboud University Nijmegen Medical Centre, Nijmegen, The Netherlands

J. Agnes Brunnekreef · J. Ormel · A. J. Oldehinkel Interdisciplinary Center for Psychiatric Epidemiology, University Medical Center Groningen,

University of Groningen, Groningen, The Netherlands

J. Agnes Brunnekreef · R. B. Minderaa .

C. A. Hartman - A. J. Oldehinkel

Department of Psychiatry, University Medical Center

Groningen, University of Groningen, Groningen,

The Netherlands

\section{A. C. Huizink}

Behavioural Science Institute, Radboud University Nijmegen, Nijmegen, The Netherlands

\section{A. C. Huizink}

Faculty of Behavioral and Social Sciences,

University of Amsterdam, Amsterdam, The Netherlands
10-12 years) from the TRacking Adolescents' Individual Lives Survey (TRAILS). Affective problems were measured with the DSM-oriented Affective Problems scale of the Youth Self Report at wave 1 (baseline assessment), wave 2 (after 2.5 years) and wave 3 (after 5 years). Cross-sectionally, baseline response speed, response time variability, response inhibition and working memory were associated with baseline affective problems in girls, but not in boys. Longitudinally, enhanced response time variability predicted affective problems after 2.5 and 5 years in girls, but not in boys. Decreased response inhibition predicted affective problems after 5 years follow-up in girls, and again not in boys. The results are discussed in light of recent insights in gender differences in adolescence and state-trait issues in depression.

Keywords Depression - Affective problems · Neuropsychology $\cdot$ Gender $\cdot$ Adolescence $\cdot$ Cohort

\section{Introduction}

Affective problems and neurocognitive problems co-occur in depression but the relationship between these domains is still poorly understood. The characteristic 'diminished ability to think or concentrate, or indecisiveness' is a criterium of Major Depressive Disorder (MDD), next to criteria that represent affective and somatic problems [1]. To better understand the phenomenology and etiology of depression, researchers have been investigating the neurocognitive profile of depression. They found that adult patients with MDD show neurocognitive impairments in attentional and executive functioning, short-term memory, working memory and psychomotor speed [2, 3].

Data about the presence of neurocognitive impairments in depressed adolescents are scarce and inconclusive. MDD 
and Dysthymic Disorder (DD), i.e., a more chronic state of depression during at least 1 year, have been found to be associated with impaired spatial working memory in adolescent girls [4]. Baseline response speed was impaired in a sample of adolescent girls with MDD [4], but not in a mixed sample of boys and girls from the same age group [5]. Both MDD and DD appeared to be associated with impaired verbal working memory [5] and with reduced speed on tasks that appealed to attentional flexibility [6]. Response inhibition deficits were not identified on a Go/No go Task $[5,7]$, whereas performance on the Stroop Task indicated impaired response inhibition and interference control [7]. Interference control was not shown with the Flanker task [8], and whereas one study identified an enhanced response time variability [7], another study did not [5].

The discrepancies between these study results may be explained by variation in neurocognitive tasks administered, and by differences in sample characteristics, such as variation in the severity of depression of the participants and variation in gender. Despite these discrepancies, a strikingly consistent finding is that neurocognitive impairments were primarily observed in girls but not in boys with depression. Further, it is remarkable that the association between neurocognitive functioning and depression has mainly been studied in cross-sectional case-control designs in which neurocognitive performance of clinically depressed patients was compared to that of non- or neverdepressed controls. Case-control studies are designed to indicate associations, i.e., coincidence of depression and neurocognitive impairments, but impede conclusions about causal inferences. Longitudinal studies are needed to study whether neurocognitive impairments lead to depression, or alternatively, whether depression leads to neurocognitive impairments.

A framework that is commonly intertwined with the cause-coincidence distinction is the state-trait discussion. The state-trait dichotomy originates from distinguishing stable personality traits and fluctuating state emotional reactions [9]. Applying the state-trait dichotomy to depression, neurocognitive impairment could represent a trait factor or neurocognitive marker that is already present before depression develops and will be present even after the depressive episode. This trait factor could be an early expression or one of the component causes of depression. Alternatively, neurocognitive impairment could be a state factor, coincidental with depression but not causally related, or could be due to causal factors that are shared between depression and neurocognitive impairment.

Some evidence from adult clinical populations fits the 'trait' idea in that some neurocognitive impairments continue to be present when depression is in remission [10-14]. However, impairments in remitted patients may be a consequence of a depressive episode (a 'scar effect') or a residual symptom ('state effect') rather than a premorbid trait marker [15]. Moreover, full recovery of neurocognitive functioning upon remission of adult MDD has also been reported, e.g., on verbal memory tasks [16-18], measures of attention [16, 19], and verbal fluency [16]. That supports the idea that impaired neurocognitive functioning may be at least a state effect [20] for some of the neurocognitive impairments.

Neurocognitive functioning in remitted MDD patients may yield evidence for state or trait characteristics or for scar effects, but not for causality. A study design that is more likely to generate evidence for causality is a longitudinal prospective cohort study. Cohort studies that have addressed neurocognitive impairment as a potential premorbid marker for depression are sparse and assessed only two neurocognitive functions. Speed of information processing appeared not to be a neurocognitive marker of depression after 2-year follow-up. However, episodic memory predicted depression after 2-year follow-up in a population-based adult female sample [20] and after a 3-year follow-up in a population-based adult sample with both males and females. Nevertheless, episodic memory would not be recommended for neurocognitive screening because of its low specificity and sensitivity [20, 21]. Castaneda and others [2] suggested that more prospective studies starting from young adulthood or even earlier are required to further address this issue.

Impaired neurocognitive functioning may not only be related to MDD, but may already arise with subclinical affective problems. In adolescence, subclinical affective problems are widespread, with prevalence rates ranging from 15 to $40 \%$ [22]. These affective problems include changes in sleeping and eating patterns, feeling worthless and having suicidal ideations. Impaired neurocognitive functioning is considered to be mediating the functional adaptation in depression [23, 24]. Functional adaptation is already worsened with as little as one affective problem compared with having no affective problems [25]. Accordingly, impaired neurocognitive functioning may already co-occur with subclinical affective problems. The predictive association between neurocognitive functioning and affective problems in young adolescents may be different from adults for several reasons. Compared to adulthood, adolescence is a time of substantial neurobiological changes that subserve higher cognitive functions, reasoning, interpersonal interactions, cognitive control of emotions, riskversus-reward appraisal and motivation. These changes may play a role in the susceptibility to the development of affective problems [26-28].

The susceptibility for affective problems seems to differ in girls compared to boys. The female-male prevalence ratio changes from 1:1 prepuberal to $2: 1$ after puberty [27]. This changing ratio may for at least a part be attributed to 
hormonal changes that occur during adolescence $[26,27$, 29-31]. Furthermore, just like in adults, gender differences in neurocognitive performance have repeatedly been observed in adolescents, in particular a female superiority in processing speed $[32,33]$ and a male superiority in perceptual analysis and working memory $[33,34]$. Impaired neurocognitive functioning in adolescent MDD patients has predominantly been shown in samples of girls $[4,5]$.

The objective of the present study was to examine the cross-sectional and longitudinal association between neurocognitive functioning and affective problems in a large unselected cohort of adolescents, with three assessment waves. Our first hypothesis was that neurocognitive functioning may be associated with affective problems in adolescent girls, but not in boys. Based on previous research we expected gender differences in neurocognitive functioning and possibly in the association between neurocognitive functioning and affective problems. Our second hypothesis was that neurocognitive functioning in a population-based sample of 10- to 12-year-old adolescents would predict affective problems after 2.5- and 5 -year follow-up. Gender was used as a stratifying variable because of expected gender differences in neurocognitive functioning in relation to affective problems. Furthermore, the incidence of affective problems in adolescent girls was expected to gradually outnumber the incidence in boys during the study period.

\section{Method}

Sample

The TRacking Adolescents' Individual Lives Survey (TRAILS) is a prospective cohort study of Dutch adolescents, which aims to study the development of mental health from early adolescence into adulthood. Adolescents will be assessed every $2-3$ years from age 10-12 until at least the age of 24 . The study has been approved by the Dutch Central Committee on Research Involving Human Subjects (CCMO) and informed consent has been appropriately obtained. The present study involved data from the first, second and third assessment wave of TRAILS. The first assessment $(N=2,230$, mean age $=11.1$, range 10-12 years, $50.7 \%$ girls) was a baseline assessment, the second assessment $(N=2,087$, mean age $=13.6$, range $12-15$ years, $51.2 \%$ girls) was 2.5 years after baseline, and the third assessment $(N=1,819$, mean age $=16.3$, range $14.5-18.5$ years, $52.3 \%$ girls) was 5 years after baseline assessment. Detailed information about the TRAILS sample is provided elsewhere [35, 36]. For the present study, participants were selected when self-reported problem behavior and neurocognitive functioning data were available at the first assessment $(n=2,179 ; 97.7 \%$ of the TRAILS sample). There are no indications of differences in the prevalence of affective problems or other problem domains between study participants and a reference group of non-participants from the original school population [35, 36]. However, the eight adolescents with unavailable data on problem behavior (including affective problems) performed worse on the neurocognitive measure response time variability (a standard deviation of 2.8 vs. $1.8 \mathrm{~ms}, t=$ $-3.3 ; p=0.001)$ than those with full information available. Attrition at wave two was not associated with baseline affective problems, but showed some associations with neurocognitive functioning in that study dropouts at wave 2 showed lower baseline speed at wave 1 than participants ( $p=0.031)$. Attrition at wave 3 was associated with less baseline affective problems and worse performance on all baseline neurocognitive functions (except for attentional flexibility) in dropouts compared to participants (all $p s>0.04)$. Given that baseline affective problems predict affective problems at follow-up, attrition may have caused minor bias in an overestimation of the association between baseline speed at wave 1 and affective problems at wave 2 , and an underestimation of the association between all neurocognitive functions (except for attentional flexibility) at wave 1 and affective problems at wave 3 .

Procedure and measures

\section{Neurocognitive functioning}

Neurocognitive functioning was assessed at baseline wave 1 . Based on previous research $[4,5,7]$ we included measures that cover a broad range of neurocognitive functioning, i.e., information processing. The following five measures from four tasks of the Amsterdam Neuropsychological Tasks Program (ANT) [37] were selected: (1) baseline response speed (Baseline Speed task); (2) response speed variability (Sustained Attention dot patterns task); (3) response inhibition (Visual Attention Set Shifting task), (4) attentional flexibility (Visual Attention Set Shifting task); and (5) working memory (Memory Search Letters task).

In the Baseline Speed task, a white fixation cross that is presented in the center of the screen changes into a white square after a random time interval. Children were instructed to respond to this stimulus change as fast as possible by pressing a mouse button with the index finger. Baseline response speed is calculated as the mean reaction time (RT), providing a baseline measure of the child's speed of responding to the occurrence of a stimulus.

In the Sustained Attention dot patterns task, 600 dot patterns with 3,4 of 5 dots are successively presented during approximately $15 \mathrm{~min}$. Children are required to respond to 4 dots by pressing the mouse button with their 
dominant hand ('yes' response) and to respond to 3 or 5 dots by pressing the mouse button with their non-dominant hand ('no' response). Response speed variability is computed as the within-subject standard deviation of the mean RT and may therefore be interpreted as a measure of response stability in a continuous task performance.

In the Visual Attention Set Shifting task, a horizontal bar consisting of ten squares is permanently presented in the center of the screen. In each trial, a colored square moves across the bar in a randomly varied direction (either to the left or to the right). The task consists of three parts, each requiring different responses. Part 1 requires spatially compatible responses: children are instructed to copy the direction of the movement of a green-colored square (movement to left requires pressing left mouse button and movement to right requires pressing right mouse button). Part 2 requires spatially incompatible responses: children are instructed to 'mirror' the direction of the movement of a red-colored square (movement to left requires pressing right mouse button and movement to right requires pressing left mouse button). In part 3 the color of the moving square randomly alternates between green and red. When the color of the square is green, a spatially compatible response is required (as in part 1). When the color of the square is red, a spatially incompatible response is required (as in part 2). Response inhibition is computed by subtracting the mean RT of part 1 (stimulus-response compatible situation) from the mean RT of part 2 (stimulus-response incompatible situation). Attentional flexibility reflects the central neurocognitive ability to mentally switch between two competing and unpredictable response sets. It is computed by subtracting the mean RT of the compatible responses of part 1 from the mean RT of the compatible responses of part 3 .

The Memory Search Letter task comprises three parts. Before each part, children are instructed to memorize respectively one, two or three target consonants. The subsequently presented display sets consist of four consonants in each trial. Trials that contain the complete target set require a 'yes' response (pressing mouse button with dominant hand). Trials that contain none of the target letters or an incomplete target set require a 'no' response (pressing mouse button with non-dominant hand). Working memory capacity is computed by subtracting the mean RT in response to target trials of part 1 (requiring memorization and processing of one consonant) from the mean RT in response to target trials of part 3 (requiring memorization and processing of the combination of three consonants). More detailed descriptions of the tasks can be found elsewhere [38-40].

\section{Behavior problems}

Behavior problems including affective problems were assessed at the first (baseline) assessment wave (age
10-12), the second wave (age 12-15), and the third wave (age 15-18) by the Youth Self Report (YSR/11-18) [41]. A self-report questionnaire was used because it has been shown that parents tend to underreport their children's depression and children may provide a more valid description of their emotional states than parent reports [42-44]. This questionnaire consisted of 112 items that assessed the severity of problem behaviors on a 3-point scale (range 0-2). Items measuring behavior that relates strictly to the classification system of the Diagnostic and Statistical Manual of Mental Disorders yielded six DSMscales of which one contained affective problems (13 items) [45]. Content validity of the factor affective problems on the YSR is good [46] and diagnostic accuracy is high [47]. The mean item score on the DSM-scale affective problems was calculated.

\section{Analyses}

We defined scores on reaction time (RT) on the neurocognitive tasks with an absolute $\mathrm{z}$-score greater than or equal to 4 as outliers [48] and removed these from further analyses. Depending on the neurocognitive variable, the amount of outliers ranged from 4 to $11(0.01-0.04 \%)$. Moreover, we excluded participants performing at a chance level of accuracy, i.e., making 50\% or more errors on any of the relevant task conditions. Depending on the neurocognitive variable, the amount of excluded participants ranged from 0 to $62(0.0-2.8 \%)$. In the descriptives, affective problems for boys and girls at wave 1,2, and 3 were tested on correlation and differences. Neurocognitive functions for boys and girls were tested on differences.

To test the hypotheses, regression models for boys and girls separately were built for (1) baseline response speed; (2) response speed variability; (3) response inhibition; (4) attentional flexibility; and (5) working memory. The influences of neurocognitive variables on affective problems were analyzed in separate regression models. This enabled examining the influence of neurocognitive variables unconditional of other neurocognitive variables. In the first set of five regression models, baseline affective problems (T0) were predicted by baseline neurocognitive functioning. In the second set of regression models, affective problems at $\mathrm{T} 1$ (2.5 years) were predicted by baseline neurocognitive functioning, and in the third set of regression models, affective problems at T2 (5 years) were predicted by baseline neurocognitive functioning. In the prediction of affective problems at $\mathrm{T} 1$ and $\mathrm{T} 2$, a secondary correction for baseline affective problems was performed. Finally, the relation between affective problems and error rates on the sustained attention dot patterns task, the visual attention set shifting task, and the memory search letter task was tested by correlation; tests were two-sided. 
To reduce the chance of type I errors (false-positives) a powerful Holm-Bonferroni correction was applied, taking account of the five different main associations that were studied $(k=5 ; \alpha=0.05 / k=0.01)$. After ordering the $p$ values, the smallest $p$ value was compared to $\alpha / k$ (so if $k=5, \alpha=0.05 / k=0.01$ ), the second $p$ value was compared to $\alpha / k-1$, the third to $\alpha / k-2$, etc. [49].

\section{Results}

\section{Descriptive results}

Group characteristics regarding the DSM-scale affective problems for girls and boys separately at baseline are presented in Table 1, including associations and differences between affective problems in boys and girls at the three assessment waves. The mean item score on the DSMscale affective problems on the YSR was $0.30(\mathrm{SD}=0.25)$ for girls and $0.29(\mathrm{SD}=0.25)$ for boys $(p>0.05)$ at baseline. Affective problems in girls increased significantly from T0 to T1 to T2 $(p<0.01$ and $p<0.005)$. Affective problems in boys decreased from $\mathrm{T} 0$ to $\mathrm{T} 1$ and stabilized

Table 1 Descriptives (mean, SD, nonparametric Kendall's Tau correlations) of affective problems at baseline, follow-up after 2.5year and follow-up after 5 years, change is severity of affective

\begin{tabular}{|c|c|c|c|c|c|c|c|c|c|c|}
\hline \multicolumn{3}{|c|}{ Affective problems $[N$, mean (SD)] } & \multirow{3}{*}{$\begin{array}{l}\text { Independent } \\
t \text { test }\end{array}$} & \multirow[t]{3}{*}{$p$ value } & \multicolumn{6}{|c|}{ Kendall's Tau } \\
\hline & \multirow[t]{2}{*}{ Girls } & \multirow[t]{2}{*}{ Boys } & & & \multicolumn{3}{|l|}{ Girls } & \multicolumn{3}{|l|}{ Boys } \\
\hline & & & & & Baseline & 2.5 years & 5 years & Baseline & 2.5 years & 5 years \\
\hline $\begin{array}{l}\text { Baseline } \\
\text { (T0) }\end{array}$ & $1,114,0.30(0.25)$ & $1,073,0.29(0.25)$ & 1.22 & 0.23 & 1.00 & & & 1.00 & & \\
\hline $\begin{array}{l}2.5 \text { years } \\
\text { (T1) }\end{array}$ & $1,072,0.32(0.29)$ & $1,019,0.22(0.22)$ & 8.76 & $<0.001$ & $0.35 *$ & 1.00 & & $0.37 *$ & 1.00 & \\
\hline $\begin{array}{l}5 \text { years } \\
(\mathrm{T} 2)\end{array}$ & $883,0.35(0.30)$ & $777,0.22(0.22)$ & 10.42 & $<0.001$ & $0.25 *$ & $0.38 *$ & 1.00 & $0.27 *$ & $0.39 *$ & 1.00 \\
\hline \multicolumn{11}{|c|}{ Change in severity of affective problems in boys and girls } \\
\hline & Girls & \multicolumn{2}{|c|}{ Dependent $t$ test } & \multicolumn{7}{|l|}{$p$ value } \\
\hline T1-T0 & 0.02 & \multicolumn{2}{|c|}{2.6 and -7.2} & \multicolumn{4}{|c|}{0.009 and $<0.001$} & & & \\
\hline $\mathrm{T} 2-\mathrm{T} 0$ & 0.05 & \multicolumn{2}{|c|}{4.9 and -7.2} & \multicolumn{4}{|c|}{$<0.001$ and $<0.001$} & & & \\
\hline $\mathrm{T} 2-\mathrm{T} 1$ & 0.03 & \multicolumn{2}{|c|}{3.2 and -1.1} & 0.001 and & 0.254 & & & & & \\
\hline
\end{tabular}

Neurocognitive performance at baseline (wave 1) [mean (SD)]

\begin{tabular}{|c|c|c|c|c|}
\hline & Girls & Boys & Independent $t$ test & $p$ value \\
\hline Baseline response speed & $333(49)$ & $329(42)$ & 1.89 & 0.059 \\
\hline Response time variability & $1.66(0.86)$ & $1.86(0.97)$ & -5.19 & $<0.001$ \\
\hline Response inhibition & 247 (19) & $272(21)$ & -2.94 & $<0.005$ \\
\hline Attentional flexibility & $653(25)$ & $616(25)$ & 3.49 & $<0.001$ \\
\hline Working memory & $492(26)$ & $574(31)$ & -6.80 & $<0.001$ \\
\hline
\end{tabular}

from T1 to T2 $(p<0.001$ and $p=0.25)$. Consequently, at $\mathrm{T} 1$ and $\mathrm{T} 2$, girls reported more affective problems than boys $(p<0.001)$.

Neurocognitive performance in boys and girls differed significantly, see Table 1 for details. Boys outperformed girls in attentional flexibility $(p<0.001)$, whereas girls showed less response speed variability $(p<0.001)$, better response inhibition $(p<0.005)$ and a better working memory function $(p<0.001)$ than boys. There were no differences between boys and girls in baseline response speed $(p=0.06)$. Mean error rates on the tasks ranged from 6 to 19 and did not differ between boys and girls $(p s>0.05)$. Faster reaction times were associated with higher error rates on the Sustained attention dot patterns task (girls, $r=-0.21$; boys, $r=-0.15 ; p \mathrm{~s}<0.001$ ), indicating an accuracy trade-off, but not on the memory ( $p s>0.05)$.

Affective problems and neurocognitive functioning

Results of the regression models are shown in Table 2. The cross-sectional analyses indicated that affective problems

problems in boys and girls (mean difference score and descriptives (mean, SD, $t$ test) of neurocognitive performance of boys and girls search letter task and visual attention set shifting task 
Table 2 Summary of results of regression models of neurocognitive performance $(\beta)$ on affective problems at baseline, after 2.5- and 5-year follow-up, taking account of gender

\begin{tabular}{|c|c|c|c|c|}
\hline \multirow{2}{*}{$\begin{array}{l}\text { Neurocognitive } \\
\text { variable }\end{array}$} & \multicolumn{2}{|l|}{ Girls } & \multicolumn{2}{|l|}{ Boys } \\
\hline & Unadjusted & $\begin{array}{l}\text { Adjusted } \\
\text { for baseline } \\
\text { affective } \\
\text { problems }\end{array}$ & Unadjusted & $\begin{array}{l}\text { Adjusted } \\
\text { for baseline } \\
\text { affective } \\
\text { problems }\end{array}$ \\
\hline
\end{tabular}

Association with affective problems at baseline

Baseline response speed

\begin{tabular}{|c|c|c|c|c|}
\hline$\beta$ & $0.077^{* *}$ & - & 0.048 & - \\
\hline$p$ & 0.001 & & 0.117 & \\
\hline \multicolumn{5}{|c|}{ Response time variability } \\
\hline$\beta$ & $0.095^{* * *}$ & - & 0.036 & - \\
\hline$p$ & 0.002 & & 0.242 & \\
\hline \multicolumn{5}{|c|}{ Response inhibition } \\
\hline$\beta$ & $0.076 *$ & - & -0.028 & - \\
\hline$p$ & 0.012 & & 0.366 & \\
\hline \multicolumn{5}{|c|}{ Attentional flexibility } \\
\hline$\beta$ & 0.035 & - & -0.026 & - \\
\hline$p$ & 0.255 & & 0.393 & \\
\hline \multicolumn{5}{|c|}{ Working memory } \\
\hline$\beta$ & $0.079 * *$ & - & 0.013 & - \\
\hline$p$ & 0.008 & & 0.665 & \\
\hline
\end{tabular}

Prediction of affective problems after 2.5-year follow-up Baseline response speed

\begin{tabular}{|c|c|c|c|c|}
\hline$\beta$ & 0.050 & 0.001 & 0.03 & 0.016 \\
\hline$p$ & 0.105 & 0.965 & 0.305 & 0.574 \\
\hline \multicolumn{5}{|c|}{ Response time variability } \\
\hline$\beta$ & $0.087 * *$ & 0.029 & 0.034 & 0.018 \\
\hline$p$ & 0.005 & 0.287 & 0.267 & 0.552 \\
\hline \multicolumn{5}{|c|}{ Response inhibition } \\
\hline$\beta$ & 0.054 & 0.019 & 0.004 & 0.019 \\
\hline$p$ & 0.082 & 0.468 & 0.906 & 0.492 \\
\hline \multicolumn{5}{|c|}{ Attentional flexibility } \\
\hline$\beta$ & 0.013 & 0.008 & -0.018 & -0.006 \\
\hline$p$ & 0.668 & 0.781 & 0.563 & 0.820 \\
\hline \multicolumn{5}{|c|}{ Working memory } \\
\hline$\beta$ & 0.049 & -0.002 & 0.028 & 0.019 \\
\hline$p$ & 0.113 & 0.953 & 0.380 & 0.501 \\
\hline
\end{tabular}

Prediction of affective problems after 5-year follow-up

Baseline response speed

\begin{tabular}{|c|c|c|c|c|}
\hline$\beta$ & $0.073^{*}$ & 0.046 & -0.09 & -0.17 \\
\hline$p$ & 0.030 & 0.151 & 0.810 & 0.608 \\
\hline \multicolumn{5}{|c|}{ Response time variability } \\
\hline$\beta$ & $0.082 *$ & 0.054 & 0.058 & 0.048 \\
\hline$p$ & 0.015 & 0.092 & 0.109 & 0.152 \\
\hline \multicolumn{5}{|c|}{ Response inhibition } \\
\hline$\beta$ & $0.118 * * *$ & $0.102 * * *$ & -0.006 & 0.015 \\
\hline$p$ & 0.000 & 0.000 & 0.866 & 0.656 \\
\hline \multicolumn{5}{|c|}{ Attentional flexibility } \\
\hline$\beta$ & 0.022 & 0.010 & 0.018 & 0.031 \\
\hline$p$ & 0.532 & 0.749 & 0.629 & 0.353 \\
\hline
\end{tabular}

Table 2 continued

\begin{tabular}{|c|c|c|c|c|}
\hline \multirow{2}{*}{$\begin{array}{l}\text { Neurocognitive } \\
\text { variable }\end{array}$} & \multicolumn{2}{|l|}{ Girls } & \multicolumn{2}{|l|}{ Boys } \\
\hline & Unadjusted & $\begin{array}{l}\text { Adjusted } \\
\text { for baseline } \\
\text { affective } \\
\text { problems }\end{array}$ & Unadjusted & $\begin{array}{l}\text { Adjusted } \\
\text { for baseline } \\
\text { affective } \\
\text { problems }\end{array}$ \\
\hline \multicolumn{5}{|c|}{ Working memory } \\
\hline$\beta$ & -0.009 & -0.039 & 0.024 & 0.018 \\
\hline$p$ & 0.784 & 0.228 & 0.510 & 0.585 \\
\hline
\end{tabular}

Values accepted after Holm-Bonferroni correction are in bold $* p<0.05 ; * * p<0.01 ; * * * p<0.001$

were associated with a lower baseline response speed $(\beta=0.08, p=0.001)$, more variability in response time ( $\beta=0.10, p=0.002)$, lower working memory capacity $(\beta=$ $0.08, p=0.008)$ and lower response inhibition $(\beta=0.08$, $p=0.012)$ in girls. In boys, affective problems were not associated with neurocognitive performance (all $p$ values $>0.01)$.

In the longitudinal analyses in girls, only enhanced response time variability predicted affective problems after 2.5 years in girls $(\beta=0.09, p=0.005)$. After adjustment for baseline affective problems, this predictive effect of response time variability disappeared $(\beta=0.03, p=$ 0.29 ). After 5 years follow-up, affective problems in girls were predicted by decreased response inhibition $(\beta=0.12$, $p<0.001)$ even after adjustment for the effect of baseline affective problems $(\beta=0.10, p<0.001)$. Response time variability was also a predictor in girls $(\beta=0.08$, $p=0.015)$, but not after adjustment for baseline affective problems $(\beta=0.05, p=0.09)$. In boys, neurocognitive performance did neither predict affective problems after 2.5 nor 5 years.

Error rates and affective problems

Errors on the sustained attention dot patterns task, the visual attention set shifting task and the memory search letter task were not associated with affective problems, neither at baseline, nor at follow-up after 2.5 and 5 years $(p s>0.05)$.

\section{Discussion}

The objective of the present study was to better understand the relationship between affective problems and neurocognitive functioning in adolescent boys and girls, in crosssectional and in longitudinal perspective. In line with our first hypothesis slower baseline speed, enhanced response time variability, deficient response inhibition and poor working memory were cross-sectionally associated with 
affective problems at age 10-12 years. Moreover, as we expected, this was the case for girls but not for boys. With respect to our second hypothesis, enhanced response time variability indeed predicted affective problems at 2.5- and 5 -year follow-up. Deficient response inhibition also predicted affective problems at 5-year follow-up, but not at 2.5-year follow-up.

The present findings suggest that enhanced response time variability is associated with affective problems in girls, but not in boys, and suggest that enhanced response time variability coincides with and predicts affective problems. Therefore, response time variability may be a risk factor in the causal pathway of affective problems. The question, which underlying mechanism explains this relation remains. Previous research in adults already showed that response time variability on sustained attention tasks tends to increase more quickly in depressed patients than in healthy participants, and several explanations have been offered. Depressed patients were suggested to have an increased susceptibility to fatigue, may be lacking in sustained motivation, may be unable to maintain concentration, and may be lacking physiological preparedness to react [50, 51]. An additional explanation may be that enhanced variability in response time is a neurocognitive marker of stress reactivity. Stress reactivity is a risk factor for depression that is mediated by genetic risk but primarily influenced by environmental factors, i.e., chronic stress in childhood [52, 53]. A recent study in adolescents with ADHD showed that response time variability was associated with increased cortisol levels after stress [54], which was consistent with earlier research in depressed patients showing cognitive deficits related to cortisol secretion [55, 56]. Additionally, response time variability has been associated with poor attentional control in the prefrontal cortex (PFC) [57, 58]. Under stress, PFC activity is closely related to activity of the hypothalamic pituitary adrenal (HPA) axis, and high levels of adrenergic activation were shown to have a detrimental effect on attention performance [54, 59, 60]. So, response time variability and increased stress reactivity, which is a neurocognitive risk marker for depression, may be closely related.

The present study shows that only in girls, enhanced response time variability is associated with affective problems. This is an interesting result since twice as many women than men are found to suffer from depression, and a gender difference starts to emerge in adolescence [29, 61, 62]. Furthermore, cortisol reactivity to stress differs between boys and girls [63] and daughters, not sons, of depressed parents showed aberrant cortisol reactivity to stress [64]. Sex hormone levels may play a role because these have been associated with the incidence of depression and may also influence stress reactivity by modulating the maturation, activation and feedback of the HPA axis
[65-67]. Future research should clarify the potential role of cortisol reactivity to stress in the causal pathway that links response time variability to affective problems in adolescence.

Remarkably, response inhibition did not predict affective problems in girls after 2.5 years but strongly predicted affective problems after 5 years. This may suggest a time lag in the prediction of affective problems and may suggest that impaired response inhibition in early adolescence is a prodromal factor for affective problems in late adolescence and not for affective problems in early adolescence. Lateonset depression (late adolescence and adulthood) differs from early-onset depression (childhood and early adolescence) in etiology and phenomenology. Late-onset depression is more likely attributed to genetic factors and favorable in terms of less symptom severity, less recurrences and less invalidation [68, 69].

It has been suggested that unlike response time variability, response inhibition in depression is not associated with cortisol but it may be mediated by another neurochemical system [70]. Therefore, response inhibition may be part of another causal pathway than response time variability in the prediction of affective problems. Response inhibition has been claimed to rely on dopaminergic pathways [71-73] that emerge mainly from the interaction of the prefrontal cortex (PFC) and the basal ganglia [74-76]. These dopaminergic pathways are involved in self-control and reward sensitivity that play a role in adolescent depression. In those who show impaired dopamine-related functioning in the PFC, the complexity of social relationships in late adolescence may inflict depressive symptoms [77-79]. Response inhibition may be a neurocognitive marker of the dopamine-related increased risk for depressive symptoms. Response inhibition was only predictive in girls, not in boys. This specificity is remarkable but consistent with a recent study that showed a similar gender effect in patients with autism spectrum disorders, in which response inhibition was only impaired in female patients [80].

In terms of state or trait, the present findings suggest that response time variability and response inhibition that predicted affective problems may at least partly be a trait factor. This is in line with previous studies that showed that response time variability in children and adolescents was of modest stability [81] and that response inhibition is stable in test-retest [85]. The present study shows that baseline response speed and working memory were only coincidentally associated with affective problems in the present study. Therefore, these neurocognitive functions may be state factors and may not be risk factors in the causal pathway of affective problems. Previous studies already showed that neurocognitive impairment was at least partly a state effect $[16,17,19,20]$ or at least partly a trait effect 
[10-13]. A quantification on a continuum between fully state and fully trait may be more appropriate to measure the strength of state-trait characteristics. The state-trait issue is only partly covered by the present study. Follow-up data on the neurocognitive variables were not available, only for affective problems. Therefore, the (in)stability of neurocognitive factors over time is not examined.

Neurocognitive functioning was only associated with affective problems in girls, but not in boys. Thus, gender matters. Actually, in the baseline age-cohort of 10-12 years, we identified gender differences in neurocognitive functioning, whereas the severity of affective problems did not differ between boys and girls until the age of 12.5 years (i.e., wave two and three). The latter is consistent with a previous study that concluded that prevalence rates of affective problems in boys and girls start to diverge from the age of 13 [82]. So far, little attention has been paid to the role of gender in the relationship between neurocognitive impairment and depression. An empirical study confirmed the importance of gender stratification by showing that female depressed patients had more cognitive interference and a lower visual recall than male depressed patients. These gender differences were suggested to be associated with gender differences in the laterality of hippocampal activity and in prefrontal cortex functioning [83]. A recent review proposed a vulnerability-stress model that integrated affective, biological and cognitive models to explain the emergence of the gender difference in (subclinical) depression [84]. The described cognitive vulnerabilities include rumination and depressive attributional styles. However, our results suggest that more general neurocognitive vulnerability plays a role in the genderspecific developmental trajectory of depression.

The question arises whether neurocognitive functions associated with affective problems are specific to affective problems or related to psychiatric problems in general. Increased response time variability and impaired response inhibition have also been associated with ADHD [85, 86] and bipolar disorder [87]. Impaired baseline response speed had previously been found in girls with MDD [4], but seems not specific to depression [50]. It has also been shown in children with ADHD, using exactly the same neurocognitive task [88]. With respect to working memory problems, previous research on the TRAILS sample provided evidence that working memory impairment might be a potential marker of the severity of more general (externalizing) problem behavior [38]. Additionally, it was suggested that children with only internalizing problems (which contained affective problems, anxiety problems and somatic problems together) did not differ on working memory capacity from children without problem behaviors [38]. Since the latter was in contrast with our present findings, we conducted post hoc stratified analyses within the construct of internalizing problems. Those results suggest that impaired working memory is specific to affective problems (Kendall's tau $=0.043, p<0.005$ ) and not associated with anxiety problems (Kendall's tau $=$ $0.001, p=0.93$ ) or somatic problems (Kendall's tau $=$ $-0.022, p=0.13$ ).

The present findings must be viewed in light of some limitations. We based our data on affective problems on selfreport rather than on psychiatric interviews. However, the content validity of the YSR scores on the affective problems is good [46]. Moreover, self-report has been shown to be the most relevant and valid measure to assess affective problems in adolescents, especially in girls [89]. Further, we did not include specific cognitive measures of processing emotional information, and cannot directly compare the contribution of processing of emotionally neutral and loaded stimuli.

In summary, our results add to the literature on depression in that aspects of information processing as reflected in response time variability and response inhibition are found to predict affective problems after 2.5 and 5 years in adolescent girls only. Further research into the causal pathway of affective problems and neurocognitive function should take account of gender effects.

\section{Conflict of Interest None.}

Open Access This article is distributed under the terms of the Creative Commons Attribution License which permits any use, distribution, and reproduction in any medium, provided the original author(s) and the source are credited.

\section{References}

1. Cooper J (2001) Diagnostic and statistical manual of mental disorders (4th edn, text revision) (DsM-IV-TR). Br J Psychiatry 179:85

2. Castaneda AE, Tuuio-Henriksson A, Marttunen M, Suvisaari J, Lonnqvist J (2008) A review on cognitive impairments in depressive and anxiety disorders with a focus on young adults. J Affect Disord 106(1-2):1-27

3. Levin RL, Heller W, Mohanty A, Herrington JD, Miller GA (2007) Cognitive deficits in depression and functional specificity of regional brain activity. Cogn Ther Res 31(2):211-233

4. Matthews K, Coghill D, Rhodes S (2008) Neuropsychological functioning in depressed adolescent girls. J Affect Disord 111(1): $113-118$

5. Gunther T, Holtkamp K, Jolles J, Herpertz-Dahlmann B, Konrad $\mathrm{K}$ (2004) Verbal memory and aspects of attentional control in children and adolescents with anxiety disorders or depressive disorders. J Affect Disord 82(2):265-269

6. Wilkinson PO, Goodyer IM (2006) Attention difficulties and mood-related ruminative response style in adolescents with unipolar depression. J Child Psychol Psychiatry 47(12):1284-1291

7. Cataldo MG, Nobile M, Lorusso ML, Battaglia M, Molteni M (2005) Impulsivity in depressed children and adolescents: a comparison between behavioral and neuropsychological data. Psychiatry Res 136(2-3):123-133 
8. van der Meere J, Borger NA, Pirila S, Sallee F (2011) interference control in children with first episode major depression: a brief report. Child Neuropsychol 17(1):96-104

9. Spielberger CD (1971) Trait-state anxiety and motor behavior. J Mot Behav 3(3):265-279

10. Weiland-Fiedler P, Erickson K, Waldeck T, Luckenbaugh DA, Pike D, Bonne O et al (2004) Evidence for continuing neuropsychological impairments in depression. J Affect Disord 82(2): 253-258

11. Paelecke-Habermann Y, Pohl J, Leplow B (2005) Attention and executive functions in remitted major depression patients. J Affect Disord 89(1-3):125-135

12. Kuny S, Stassen HH (1995) Cognitive performance in patients recovering from depression. Psychopathology 28(4):190-207

13. Hammar A, Lund A, Hugdahl K (2003) Long-lasting cognitive impairment in unipolar major depression: a 6-month follow-up study. Psychiatry Res 118(2):189-196

14. Ardal G, Hammar A (2011) Is impairment in cognitive inhibition in the acute phase of major depression irreversible? Results from a 10-year follow-up study. Psychol Psychother Theory Res Pract 84:141-150

15. Ormel J, Oldehinkel AJ, Nolen WA, Vollebergh W (2004) Psychosocial disability before, during, and after a major depressive episode-a 3-wave population-based study of state, scar, and trait effects. Arch Gen Psychiatry 61(4):387-392

16. Tarbuck AF, Paykel ES (1995) Effects of major depression on the cognitive function of younger and older subjects. Psychol Med 25(2):285-295

17. Biringer E, Mykletun A, Sundet K, Kroken R, Stordal KI, Lund A (2007) A longitudinal analysis of neurocognitive function in unipolar depression. J Clin Exp Neuropsychol 29(8):879-891

18. Gruber O, Zilles D, Kennel J, Gruber E, Falkai P (2011) A systematic experimental neuropsychological investigation of the functional integrity of working memory circuits in major depression. Eur Arch Psychiatry Clin Neurosci 261(3):179-184

19. Beats BC, Sahakian BJ, Levy R (1996) Cognitive performance in tests sensitive to frontal lobe dysfunction in the elderly depressed. Psychol Med 26(3):591-603

20. Simons CJP, Jacobs N, Derom C, Thiery E, Jolles J, van Os J et al (2009) Cognition as predictor of current and follow-up depressive symptoms in the general population. Acta Psychiatr Scand 120(1):45-52

21. Airaksinen E, Wahlin A, Larsson M, Forsell Y (2006) Cognitive and social functioning in recovery from depression: results from a population-based three-year follow-up. J Affect Disord 96(1-2):107-110

22. Compas BE, Ey S, Grant KE (1993) Taxonomy, assessment, and diagnosis of depression during adolescence. Psychol Bull 114(2): 323-344

23. Jaeger J, Berns S, Uzelac S, Davis-Conway S (2006) Neurocognitive deficits and disability in major depressive disorder. Psychiatry Res 145(1):39-48

24. Buist-Bouwman MA, Ormel J, de Graaf R, de Jonge P, van Sonderen E, Alonso J et al (2008) Mediators of the association between depression and role functioning. Acta Psychiatr Scand 118(6):451-458

25. Cuijpers P, de Graaf R, van Dorsselaer S (2004) Minor depression: risk profiles, functional disability, health care use and risk of developing major depression. J Affect Disord 79(1-3):71-79

26. Andersen SL, Teicher MH (2008) Stress, sensitive periods and maturational events in adolescent depression. Trends Neurosci 31(4):183-191

27. Paus T, Keshavan M, Giedd JN (2008) Why do many psychiatric disorders emerge during adolescence? Nat Rev Neurosci 9(12):947-957

28. Monk CS, McClure EB, Nelson EE, Zarahn E, Bilder RM, Leibenluft $\mathrm{E}$ et al (2003) Adolescent immaturity in attention- related brain engagement to emotional facial expressions. Neuroimage 20(1):420-428

29. Angold A, Costello EJ (2006) Puberty and depression. Child Adolesc Psychiatr Clin N Am 15(4):919-937

30. Patton GC, Hibbert ME, Carlin J, Shao Q, Rosier M, Caust J et al (1996) Menarche and the onset of depression and anxiety in Victoria, Australia. J Epidemiol Community Health 50(6):661666

31. Hayward C, Sanborn K (2002) Puberty and the emergence of gender differences in psychopathology. J Adolesc Health 30(4): 49-58

32. Camarata S, Woodcock R (2006) Sex differences in processing speed: developmental effects in males and females. Intelligence 34(3):231-252

33. Waber DP, De Moor C, Forbes PW, Almli CR, Botteron KN, Leonard G et al (2007) The NTH MRI study of normal brain development: performance of a population based sample of healthy children aged 6 to 18 years on a neuropsychological battery. J Int Neuropsychol Soc 13(5):729-746

34. Reynolds MR, Keith TZ, Ridley KP, Patel PG (2008) Sex differences in latent general and broad cognitive abilities for children and youth: evidence from higher-order MG-MACS and MIMIC models. Intelligence 36(3):236-260

35. de Winter A, Oldehinkel AJ, Veenstra R, Brunnekreef JA, Verhulst FC, Ormel J (2005) Evaluation of non-response bias in mental health determinants and outcomes in a large sample of pre-adolescents. Eur J Epidemiol 20(2):173-181

36. Huisman M, Oldehinkel AJ, de Winter A, Minderaa RB, de Bildt A, Huizink AC et al (2008) Cohort profile: The Dutch TRacking Adolescents Individual Lives Survey; TRAILS. Int J Epidemiol 37(6): 1227-1235

37. de Sonneville LMJ (1999) Amsterdam neuropsychological tasks: a computer-aided assessment program. In: den Brinker BPLM, Beek PJ, Brand AN, Maarse FJ, Mulder LJM (eds) Cognitive ergonomics, clinical assessment, and computer-assisted learning: computers in psychology, vol 6. Swets and Zeitlinger, Lisse, pp 187-203

38. Brunnekreef JA, de Sonneville LMJ, Althaus M, Minderaa RB, Oldehinkel AJ, Verhulst FC et al (2007) Information processing profiles of internalizing and externalizing behavior problems: evidence from a population-based sample of preadolescents. J Child Psychol Psychiatry 48(2):185-193

39. Slaats-Willemse D, Swaab-Barneveld H, de Sonneville L, van der Meulen E, Buitelaar J (2003) Deficient response inhibition as a cognitive endophenotype of ADHD. J Am Acad Child Adolesc Psychiatry 42(10): 1242-1248

40. Slaats-Willemse DIE, de Sonneville LMJ, Swaab-Barneveld HJT, Buitelaar JK (2007) Family-genetic study of executive functioning in attention-deficit/hyperactivity disorder: evidence for an endophenotype? Neuropsychology 21(6):751-760

41. Achenbach (1991) Manual for the Youth Self Report and 1991 profile. Department of Psychiatry, University of Vermont, Burlington, VT

42. Stanger C, Lewis M (1993) Agreement among parents, teachers, and children on internalizing and externalizing behavior problems. J Clin Child Psychol 22(1):107-115

43. Garber J, Keiley MK, Martin NC (2002) Developmental trajectories of adolescents' depressive symptoms: predictors of change. J Consult Clin Psychol 70(1):79-95

44. Gould MS, Bird H, Jaramillo BS (1993) Correspondence between statistically derived behavior problem syndromes and child psychiatric diagnoses in a community sample. J Abnorm Child Psychol 21(3):287-313

45. Achenbach TM, Dumenci L, Rescorla LA (2003) DSM-oriented and empirically based approaches to constructing scales from the same item pools. J Clin Child Adolesc Psychol 32(3):328-340 
46. Ferdinand RF (2008) Validity of the CBCL/YSR DSM-IV scales anxiety problems and affective problems. J Anxiety Disord 22(1):126-134

47. Aebi M, Metzke CW, Steinhausen HC (2009) Prediction of major affective disorders in adolescents by self-report measures. J Affect Disord 115(1-2):140-149

48. Stevens JP (2002) Applied multivariate statistics for the social sciences, 4th edn. Lawrence Erlbaum, New Jersey

49. Holm S (1979) A simple sequentially rejective multiple test procedure. Scand J Stat 6(2):65-70

50. Marazziti D, Consoli G, Picchetti M, Carlini M, Faravelli L (2010) Cognitive impairment in major depression. Eur J Pharmacol 626(1):83-86

51. Miller WR (1975) Psychological deficit in depression. Psychol Bull 82(2):238-260

52. Goodyer IM, Croudace T, Dudbridge F, Ban M, Herbert J (2010) Polymorphisms in BDNF (Va166Met) and 5-HTTLPR, morning cortisol and subsequent depression in at-risk adolescents. $\mathrm{Br} \mathbf{J}$ Psychiatry 197(5):365-371

53. Hammen C, Brennan PA, Keenan-Miller D, Hazel NA, Najman JM (2010) Chronic and acute stress, gender, and serotonin transporter gene-environment interactions predicting depression symptoms in youth. J Child Psychol Psychiatry 51(2):180-187

54. Lee SH, Shin DW, Stein MA (2010) Increased cortisol after stress is associated with variability in response time in ADHD children. Yonsei Med J 51(2):206-211

55. Hinkelmann K, Moritz S, Botzenhardt J, Riedesel K, Wiedemann $\mathrm{K}$, Kellner $\mathrm{M}$ et al (2009) Cognitive impairment in major depression: association with salivary cortisol. Biol Psychiatry 66(9):879-885

56. Michopoulos I, Zervas IM, Pantelis C, Tsaltas E, Papakosta VM, Boufidou F et al (2008) Neuropsychological and hypothalamicpituitary-axis function in female patients with melancholic and non-melancholic depression. Eur Arch Psychiatry Clin Neurosci 258(4):217-225

57. Castellanos FX, Sonuga-Barke EJS, Milham MP, Tannock R (2006) Characterizing cognition in ADHD: beyond executive dysfunction. Trends Cogn Sci 10(3):117-123

58. Hurks PPM, Adam JJ, Vles JSH, Kalff AC, Crolla IFAM, Hendriksen JGM et al (2005) Controlled visuomotor preparation deficits in attention-deficit/hyperactivity disorder. Neuropsychology 19(1):66-76

59. Ramos BP, Arnsten AFT (2007) Adrenergic pharmacology and cognition: focus on the prefrontal cortex. Pharmacol Ther 113(3): $523-536$

60. Dunn AJ, Swiergiel AH, Palamarchouk V (2004) Brain circuits involved in corticotropin-releasing factor-norepinephrine interactions during stress. Stress: Curr Neuroendocr Genetic Approaches 1018:25-34

61. Angold A, Erkanli A, Silberg J, Eaves L, Costello EJ (2002) Depression scale scores in 8-17-year-olds: effects of age and gender. J Child Psychol Psychiatry 43(8):1052-1063

62. Hankin BL, Abramson LY (1999) Development of gender differences in depression: description and possible explanations. Ann Med 31(6):372-379

63. Bouma EMC, Riese H, Ormel J, Verhulst FC, Oldehinkel AJ (2009) Adolescents' cortisol responses to awakening and social stress; effects of gender, menstrual phase and oral contraceptives. The TRAILS study. Psychoneuroendocrinology 34(6):884-893

64. Bouma EMC, Riese H, Ormel J, Verhulst FC, Oldehinkel AJ (2011) Self-assessed parental depressive problems are associated with blunted cortisol responses to a social stress test in daughters. The TRAILS Study. Psychoneuroendocrinology 36(6):854-863

65. Naninck EFG, Lucassen PJ, Bakker J (2011) Sex differences in adolescent depression: do sex hormones determine vulnerability? J Neuroendocrinol 23(5):383-392
66. McCormick CM, Mathews IZ, Thomas C, Waters P (2010) Investigations of HPA function and the enduring consequences of stressors in adolescence in animal models. Brain Cogn 72(1): $73-85$

67. Oldehinkel AJ, Bouma EMC (2011) Sensitivity to the depressogenic effect of stress and HPA-axis reactivity in adolescence: a review of gender differences. Neurosci Biobehav Rev 35(8): $1757-1770$

68. Tully EC, Iacono WG, Mcgue M (2010) Changes in genetic and environmental influences on the development of nicotine dependence and major depressive disorder from middle adolescence to early adulthood. Dev Psychopathol 22(4):831-848

69. Hammen C, Brennan PA, Keenan-Miller D, Herr NR (2008) Early onset recurrent subtype of adolescent depression: clinical and psychosocial correlates. J Child Psychol Psychiatry 49(4): 433-440

70. Gomez RG, Posener JA, Keller J, DeBattista C, Solvason B, Schatzberg AF (2009) Effects of major depression diagnosis and cortisol levels on indices of neurocognitive function. Psychoneuroendocrinology 34(7):1012-1018

71. Colzato LS, van den Wildenberg PM, van Wouwe NC, Pannebakker MM, Hommel B (2009) Dopamine and inhibitory action control: evidence from spontaneous eye blink rates. Exp Brain Res 196(3):467-474

72. Mink JW (1996) The basal ganglia: focused selection and inhibition of competing motor programs. Prog Neurobiol 50(4):381-425

73. Mink JW (2003) The basal ganglia and involuntary movementsimpaired inhibition of competing motor patterns. Arch Neurol 60(10): $1365-1368$

74. Aron AR, Poldrack RA (2005) The cognitive neuroscience of response inhibition: relevance for genetic research in attentiondeficit/hyperactivity disorder. Biol Psychiatry 57(11):1285-1292

75. Miller EK, Cohen JD (2001) An integrative theory of prefrontal cortex function. Annu Rev Neurosci 24:167-202

76. van den Wildenberg WPM, van Boxtel GJM, van der Molen MW, Bosch DA, Speelman JD, Brunia CHM (2006) Stimulation of the subthalamic region facilitates the selection and inhibition of motor responses in Parkinson's disease. J Cogn Neurosci 18(4):626-636

77. Otten R, Barker ED, Maughan B, Arseneault L, Engels RCME (2010) Self-control and its relation to joint developmental trajectories of cannabis use and depressive mood symptoms. Drug Alcohol Depend 112(3):201-208

78. Davey CG, Yucel M, Allen NB (2008) The emergence of depression in adolescence: development of the prefrontal cortex and the representation of reward. Neurosci Biobehav Rev 32(1):1-19

79. Forbes EE (2009) Where's the fun in that? Broadening the focus on reward function in depression. Biol Psychiatry 66(3):199-200

80. Lemon JM, Gargaro B, Enticott PG, Rinehart NJ (2011) Brief report: executive functioning in autism spectrum disorders: a gender comparison of response inhibition. J Autism Dev Disord 41(3):352-356

81. Zabel TA, von Thomsen C, Cole C, Martin R, Mahone EM (2009) Reliability concerns in the repeated computerized assessment of attention in children. Clin Neuropsychol 23(7): 1213-1231

82. Jose PE, Brown I (2008) When does the gender difference in rumination begin? Gender and age differences in the use of rumination by adolescents. J Youth Adolesc 37(2):180-192

83. Sarosi A, Gonda X, Balogh G, Faludi G (2008) Gender differences in patterns of neurocognitive impairment during the acute phase of major depression. Eur Neuropsychopharmacol 18:S303S304

84. Hyde JS, Mezulis AH, Abramson LY (2008) The ABCs of depression: Integrating affective, biological, and cognitive 
models to explain the emergence of the gender difference in depression. Psychol Rev 115(2):291-313

85. Epstein JN, Langberg JM, Rosen PJ, Graham A, Narad ME, Antonini TN et al (2011) Evidence for higher reaction time variability for children with ADHD on a range of cognitive tasks including reward and event rate manipulations. Neuropsychology 25(4):427-441

86. Pauli-Pott U, Becker K (2011) Neuropsychological basic deficits in preschoolers at risk for ADHD: a meta-analysis. Clin Psychol Rev 31(4):626-637

87. Brotman MA, Rooney MH, Skup M, Pine DS, Leibenluft E (2009) Increased intrasubject variability in response time in youths with bipolar disorder and at-risk family members. J Am Acad Child Adolesc Psychiatry 48(6):628-635

88. Rommelse NNJ, Altink ME, Oosterlaan J, Beem L, Buschgens CJM, Buitelaar J et al (2008) Speed, variability, and timing of motor output in ADHD: which measures are useful for endophenotypic research? Behav Genet 38(2):121-132

89. Sourander A, Helstela L, Helenius H (1999) Parent-adolescent agreement on emotional and behavioral problems. Soc Psychiatry Psychiatr Epidemiol 34(12):657-663 